\title{
Two heterozygous Cav3.2 channel mutations in a pediatric chronic pain patient: recording condition-dependent biophysical effects
}

\author{
Ivana A. Souza ${ }^{1}$ - Maria A. Gandini ${ }^{1} \cdot$ Miranda M. Wan ${ }^{1} \cdot$ Gerald W. Zamponi ${ }^{1}$
}

Received: 15 November 2015 / Revised: 14 December 2015 / Accepted: 16 December 2015

(C) Springer-Verlag Berlin Heidelberg 2015

\begin{abstract}
We report expression system-dependent effects of heterozygous mutations (P769L and A1059S) in the Cav3.2 CACNA1H gene identified in a pediatric patient with chronic pain and absence seizures. The mutations were introduced individually into recombinant channels and then analyzed by means of electrophysiology. When both mutants were coexpressed in tsA-201 cells, we observed a loss of channel function, with significantly smaller current densities across a wide range of voltages $(-40$ to $+20 \mathrm{mV})$. In addition, when both mutant channels were co-expressed, the channels opened at a more depolarizing potential with a $\sim 5-\mathrm{mV}$ right shift in the half-activation potential, with no changes in half-inactivation potential and the rate of recovery from inactivation. Interestingly, when both mutants were co-expressed in the neuronalderived CAD cells in a different extracellular milieu, the effect was remarkably different. Although not statistically significant $(p<0.07)$, current densities appeared augmented compared to wild-type channels and the difference in the halfactivation potential was lost. This could be attributed to the replacement of extracellular sodium and potassium with tetraethylammonium chloride. Our results show that experimental conditions can be a confounding factor in the biophys-
\end{abstract}

Ivana A. Souza and Maria A. Gandini contributed equally to this work.

Gerald W. Zamponi

zamponi@ucalgary.ca

1 Department of Physiology and Pharmacology, Alberta Children's Hospital Research Institute, Cumming School of Medicine, University of Calgary, 3330 Hospital Dr. NW, Calgary T2N 4N1, Canada ical effects of T-type calcium channel mutations found in certain neurological disorders.

Keywords Calcium channel $\cdot$ T-type $\cdot$ Epilepsy $\cdot$ Pain · Mutation $\cdot$ HEK cells

\section{Introduction}

The $C A C N A 1 H$ gene encodes the pore-forming $\alpha 1$ subunit of the T-type calcium channel isoform Cav3.2 [1]. T-type channels are a family of low-voltage-activated (LVA) $\mathrm{Ca}^{2+}$ channels that are important regulators of neuronal excitability. They can be activated by small depolarizations of the plasma membrane, and $\mathrm{Ca}^{2+}$ influx through these channels triggers low-threshold spikes that facilitate the generation of $\mathrm{Na}^{+}$-dependent bursts of action potentials [2]. This feature is particularly important in the thalamocortical network, where T-type channels contribute to its burst firing and oscillatory behavior [3] and are known to play a role in idiopathic generalized epilepsies (IGEs) [4]. In fact, a number of mutations in human Cav3.2 channels have been linked to epileptic disorders such as childhood absence epilepsy (CAE), febrile seizures (FS), myoclonic-astatic epilepsy (MAE), and juvenile absence epilepsy (JAE) [5-8]. In addition to regulating neuronal firing, T-type channels are also known to contribute to neurotransmitter release at dorsal horn synapses, playing an important role in the transmission of pain signals $[9,10]$. Therefore, blocking Cav3.2 channels or knocking down its expression in nociceptive dorsal root ganglion (DRG) neurons results in antinociceptive, antihyperalgesic, and anti-allodynic effects [11-13]. Although upregulation and increased activity of Cav3.2 channels are associated with chronic pain in animal models [14-16], no 
mutations in the human CACNA1H Cav3.2 gene have been linked to pain conditions in patients so far.

A 14-year-old female patient presented a number of chronic conditions including absence epilepsy, body-wide chronic pain, irritable bowel, asthma, and reflux. The patient was originally asymptomatic, but her symptoms started after a case of mononucleosis at the age of 9. Whole exome sequence analysis revealed two heterozygous missense mutations in the CACNA1H gene, c.2306C $>$ T (p.P769L), inherited from her mother, and c.3175G $>\mathrm{T}$ (p.A1059S), inherited from her father. The mutations were not predicted to be pathogenic using two different programs (PolyPhen, SIFT), although the variant A1059S has been previously associated to epilepsy in at least three families [6]. The parents who carry the heterozygous individual mutations are asymptomatic. In a cohort of 60 , 000 control subjects listed in Exome Aggregation Consortium (ExAC) database, the A1059S variant appears 720 times, but the P769L mutation is rare (five occurrences).

Considering the involvement of Cav3.2 channels in both epilepsy and chronic pain, we investigated the functional consequences of having both the patient's missense mutations expressed as separate cDNA constructs in tsA-201 and neuronal CAD cells.

\section{Material and methods}

\section{Patient and exome sequencing}

An exome sequencing report from the health care provider was provided to us by the patient. According to the documentation, exome sequencing was performed using the Agilent SureSelect Human all Exon $50 \mathrm{Mb}$ XT kit and an Illumina HiSeq2500. In total, 10,188,523,696 bases of sequence were generated and uniquely aligned to both the human reference genome and mitochondrial genome, generating a mean coverage of $135 \times$ per base within the RefSeq protein-coding bases of the human genome.

\section{Consent}

Informed consent was obtained from the mother for the publication of this article.

\section{Molecular cloning}

Wild-type (wt) human HA-tagged Cav3.2 $\alpha 1$ subunit [accession NM 021098.2] in pcDNA3.1 was used for insertion of P769L and A1059S missense mutations. Site-directed mutagenesis was performed using the QuikChange site-directed mutagenesis kit (Agilent Technologies) as per manufacturer's instructions. After mutagenesis, each construct was validated by sequencing of the cloned region.

\section{Cell culture and transient transfection}

Human embryonic kidney tsA-201 and neuronal-derived CAD cells were cultured and transiently transfected using the calcium phosphate method as described previously [17]. Cells were plated on glass coverslips and transfected with either $3 \mu \mathrm{g}$ of wtCav3. $2 \mathrm{cDNA}, 3 \mu \mathrm{g}$ of cDNA for the mutants when they were individually expressed, or $1.5 \mu \mathrm{g}$ of cDNA of each Cav3.2 mutant (P769L + A1059S) when co-expressed, and $0.5 \mu \mathrm{g}$ of pEGFP was included to identify transfected cells. CAD cells were grown at $37^{\circ} \mathrm{C}$ for $72 \mathrm{~h}$ after transfection while tsA-201 cells were kept at $30^{\circ} \mathrm{C}$ for the same period of time.

\section{Cell surface biotinylation}

Cells transfected with wtCav3.2 and mutants were washed with ice-cold HEPES-based saline solution (HBSS) and incubated on ice for $15 \mathrm{~min}$ to stop trafficking of proteins. Surface proteins were biotinylated for $1 \mathrm{~h}$ on ice with $1 \mathrm{mg} / \mathrm{ml}$ of EZLink Sulfo-NHS-SS-Biotin (Thermo Scientific). The reaction was quenched with $100 \mathrm{mM}$ glycine for $15 \mathrm{~min}$, and cells were lysed in modified RIPA buffer (in millimolar: 50 Tris, $150 \mathrm{NaCl}, 5$ EDTA, $1 \%$ Triton X-100, $1 \%$ NP-40, $0.2 \%$ SDS, pH 7.4) for $45 \mathrm{~min}$. Protein quantification was performed using the Bio-Rad protein assay dye, and $2 \mathrm{mg}$ of lysates was incubated with $100 \mu$ l of Neutravidin beads (Thermo Scientific) for 1.5 hour at $4{ }^{\circ} \mathrm{C}$. Beads were washed three times with lysis buffer and proteins eluted with $2 \times$ Laemmli sample buffer. Biotinylated proteins and lysates were resolved by SDS-PAGE and analyzed by western blot using the antibodies 1/500 anti-Cav3.2 (Novus Biologicals) and 1/5000 anti-Na ${ }^{+} / \mathrm{K}^{+}$ATPase (Abcam). Quantification of surface and total expression was performed using the ImageJ software (National Institute of Health). For each experiment, background was subtracted and integrated density of bands was measured and normalized by $\mathrm{Na}^{+} / \mathrm{K}^{+}$ATPase signal for loading control.

\section{Voltage clamp recordings}

Electrophysiological recordings were performed according to the whole cell configuration of the patch-clamp technique $72 \mathrm{~h}$ after transfection at room temperature $\left(22-24^{\circ} \mathrm{C}\right)$. Unless otherwise stated, currents in tsA-201 cells were recorded using the following external solution (in $\mathrm{mM}$ ): $10 \mathrm{BaCl}_{2}, 120 \mathrm{NaCl}$, $5 \mathrm{KCl}, 1 \mathrm{MgCl}_{2}, 10$ Tea-Cl, 10 HEPES, and 10 glucose ( $\mathrm{pH}$ 7.2). For $C A D$ cells, the external recording solution contained the following (in mM): $10 \mathrm{BaCl}_{2}, 1 \mathrm{MgCl}_{2}, 140$ Tea-Cl, 10 HEPES, and 10 glucose ( $\mathrm{pH}$ 7.2). Patch pipettes were filled with a solution containing the following (in millimolar): 110 $\mathrm{CsCl}, 2.5 \mathrm{MgCl}_{2}, 10$ EGTA, 10 HEPES, 5 glucose, 3 ATP, 0.5 GTP (pH 7.4). 
Currents were recorded using an Axopatch 200B amplifier (Molecular Devices), by applying 250-ms pulses between -90 and $40 \mathrm{mV}$ in $10-\mathrm{mV}$ increments from a holding potential $\left(V_{\mathrm{h}}\right)$ of $-100 \mathrm{mV}$. Density current-voltage $(I-V)$ relationships were generated from the peak current obtained during the pulses divided by whole cell capacitance. The $I-V$ relationships were fitted with a Boltzmann equation of the following form: $I=G$ $\max \times\left(V_{m}-V_{r}\right) /\left(1+\exp \left(-\left(V_{m}-V_{1 / 2}\right) / k\right)\right)$, where I is the peak current, $V_{m}$ is the membrane potential, $V_{1 / 2}$ is the voltage for half activation, $V_{r}$ is the reversal potential, and $k$ is the slope factor.

Steady-state inactivation was measured by applying 1-s conditioning pulses from -100 to $-30 \mathrm{mV}$ in $10-\mathrm{mV}$ increments followed by a 25 -ms test pulse to $-20 \mathrm{mV}$. Curves were fitted with the equation $I / I_{\max }=1 /\left(1+\exp \left(-\left(V_{\mathrm{m}}-V_{1 / 2}\right) / k\right)\right)$, where $V_{1 / 2}$ is the voltage for half inactivation, and $k$ is the slope factor.

Recovery from inactivation was evaluated by applying two 25 -ms test pulses ( $\mathrm{P} 1$ and $\mathrm{P} 2$ ) to $-20 \mathrm{mV}$ varying the time between them from 40 to $200 \mathrm{~ms}$ every $40 \mathrm{~ms}$, and from $400 \mathrm{~ms}$ to $1.2 \mathrm{~s}$ every $200 \mathrm{~ms}$. P2/P1 was plotted as a function of time.

\section{Data analysis}

Data were analyzed using Clampfit 10.3 software (Molecular Devices) and fit using Sigma Plot. All averaged data are plotted as mean \pm SE. Statistical analysis was performed using Student's $t$ test, or one-way ANOVA followed by Tukey's test, and $p<0.05$ was considered significant.

\section{Results}

The Cav3.2 $\alpha 1$ subunit consists of four repeated domains (IIV), each containing six transmembrane regions (S1-S6) with a voltage sensor domain (S1-S4) and a pore loop between S5 and S6. Two missense mutations in the Cav3.2 CACNA1H gene were identified in a patient with body-wide chronic pain and absence epilepsy by whole exome sequencing. The mutation P769L is located in the intracellular I-II loop, while the A1059S is in the II-III loop of the channel (Fig. 1). Because the patient is heterozygous for both mutations, all expression studies involved co-expression of two separate cDNA constructs, each carrying one mutation.

\section{Biophysical properties of wtCav3.2 and mutant channels (P769L + A1059S) expressed in tsA-201 cells.}

To assess the biophysical properties of the Cav3.2 mutations identified in the patient, we performed whole-cell patch clamp recordings of HA-tagged Cav3.2 channels individually containing the missense mutations P769L and A1059S (coexpressed in tsA-201 cells). For these recordings, the

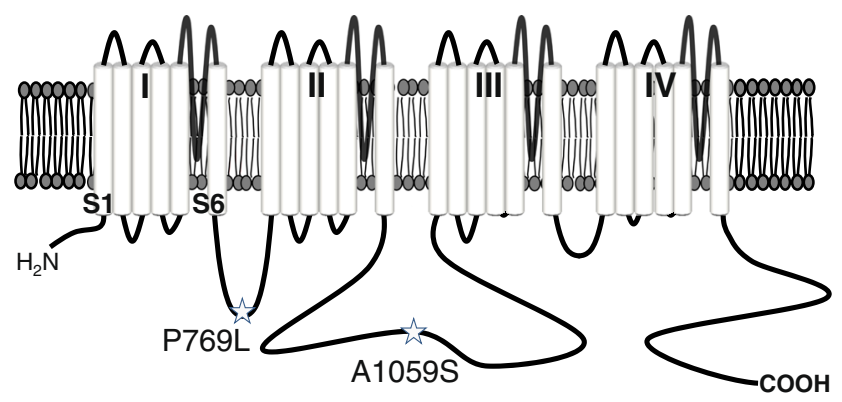

Fig. 1 Location of the P769L and A1059S mutations in the secondary structure of the Cav $3.2 \alpha 1$ subunit. The stars indicate the approximate loci of the mutations

extracellular bath solution contained $10 \mathrm{mM}$ barium as the charge carrier, as well as $120 \mathrm{mM} \mathrm{NaCl}$ and $5 \mathrm{mM} \mathrm{KCl}$, along with $1 \mathrm{mM} \mathrm{MgCl} 2,10 \mathrm{mM}$ Tea-Cl, $10 \mathrm{mM}$ HEPES, and $10 \mathrm{mM}$ glucose ( $\mathrm{pH}$ 7.2) (see "Material and methods"). Currents were elicited by stepping from a holding potential of $100 \mathrm{mV}$ to various test voltages. Average current densities $(\mathrm{pA} / \mathrm{pF})$ as a function of membrane voltage were consistently and significantly smaller across a range of voltages (from -40 to +20 , Fig. 2a) when compared to wtCav3.2. Boltzmann parameters describing the activation characteristics were also modified in cells transfected with both mutants. The halfactivation potential exhibited a statistically significant right shift $(\sim 5 \mathrm{mV})$ with a change in the slope factor (Table 1; Fig. 2b) without affecting the reversal potential, suggesting a reduction of function. Hence, when both mutants P769L and A1059S are expressed together, stronger depolarizations are required to open the channels due to a shift in the activation potential and voltage sensitivity. This in turn produces a decrease in $\mathrm{Ca}^{2+}$ influx compared to wild-type channels.

Half-inactivation voltage and time course of recovery from inactivation were not different in cells expressing both mutants (P769L+A1059S) compared to wtCav3.2 (Fig. 2c, d). There was, however, a small change in the slope of the steadystate inactivation curve (Table 1). When we recorded the mutants individually, P769L did not show any differences in current density or Boltzmann activation parameters (Table 1), while the A1059S mutant presented significant smaller current densities, although not as robust as when both mutants were expressed together, and a similar depolarizing shift, as described by our group previously [6] (Table 1).

To determine if the differences in current density between wtCav3.2 and mutants were caused by reduced expression of the channels at the plasma membrane, we performed cell surface biotinylation experiments followed by western blot analysis. Figure 3 a shows that surface expression of mutant channels (expressed either alone or together) do not appear to be different from wild-type channels, suggesting that the observed effects were due to altered channel properties. Figure $3 \mathrm{~b}$ depicts the corresponding total expression. Quantification of surface and total expression of the channels can be 
Fig. 2 P769L and A1059S coexpressed in tsA-201 cells present a loss of function. a Average current densities $(\mathrm{pA} / \mathrm{pF})$ as a function of voltage in tsA-201 cells transfected with wtCav3.2 or P769L and A1059S channels as indicated. b Voltage dependence of current activation at steady state in tsA-201 cells expressing wtCav3.2 (black circles) and P769L and A1059S channels (gray circles). c Voltage dependence of current inactivation at steady state in tsA201 cells expressing wtCav3.2 or P769L plus A1059S channels as indicated. d Comparison of the time course of recovery from inactivation for wtCav3.2 or P769L plus A1059S channels a
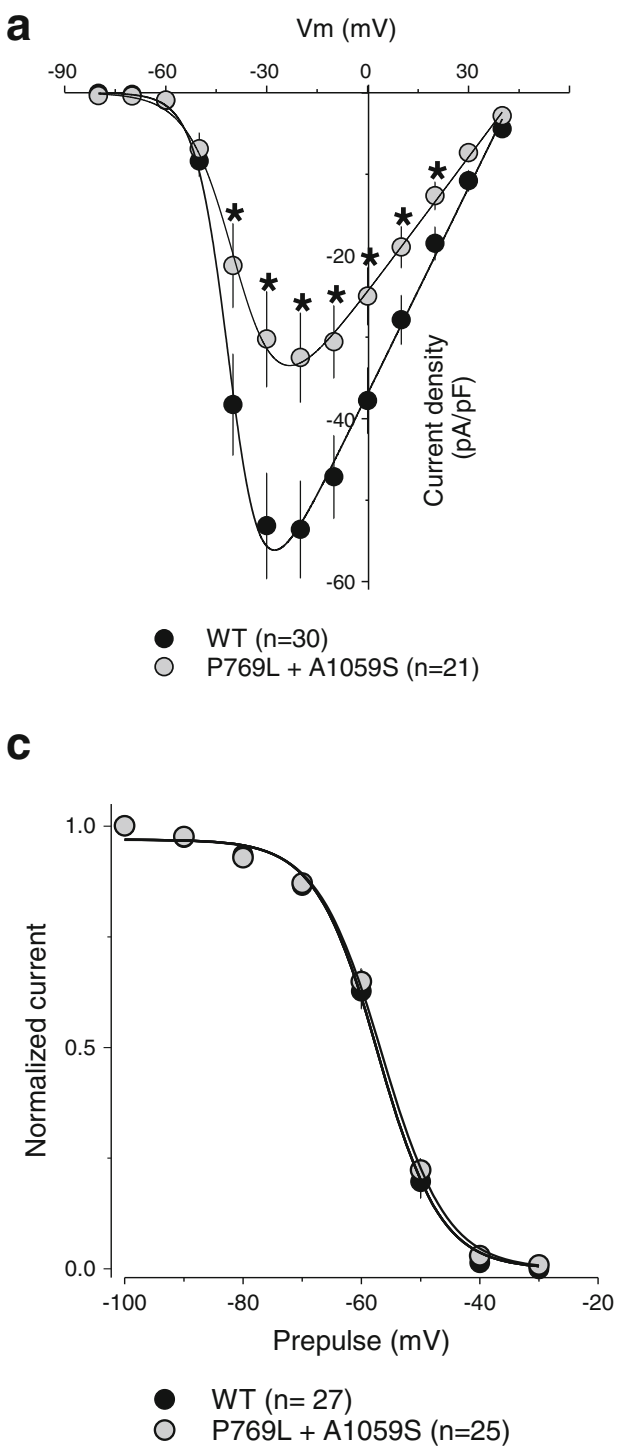

b

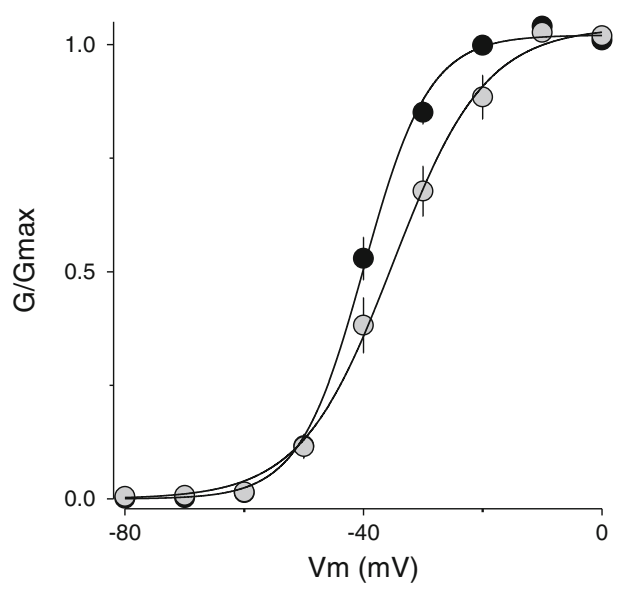

d

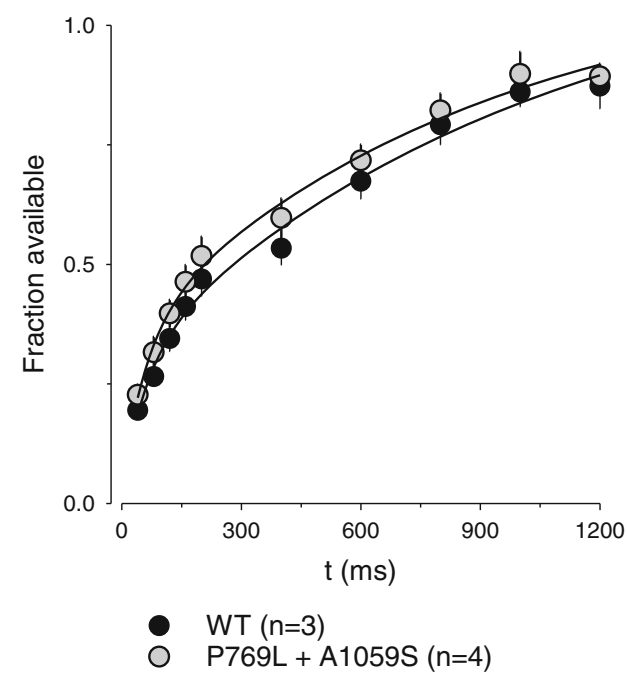

seen in Fig. 3c, d, and although there appears to be a decrease in surface and total expression of mutant A1059S, it is not statistically significant ( $p<0.12$ and $p<0.19$, respectively, analyzed by one-way ANOVA followed by Tukey's test).

\section{Biophysical properties of wtCav3.2 and mutant channels (P769L + A1059S) expressed in CAD cells}

CAD cells are a mouse catecholaminergic cell line that express neuron-specific proteins like synaptic vesicle proteins, resembling a neuronal environment [18]. To investigate the effects of the two missense mutations in this milieu, we transfected CAD cells with either wtCav3.2 channels or both mutants (P769L + A1059S) and recorded their whole-cell $\mathrm{Ba}^{2+}$ currents (Fig. 4a, b). To avoid contamination of the recordings from endogenous sodium and potassium channels, we eliminated sodium and potassium ions and instead raised the concentration of extracellular tetraethylammonium (TEA) to $140 \mathrm{mM}$. Figure $4 \mathrm{c}$ depicts the current density-voltage relationship. Although not statistically significant $(p<0.07$, at $-20 \mathrm{mV}$ ), cells expressing both mutants had a slight increase in current density compared to wild-type channels, in apparent contradiction of our results from tsA-201 cells. Boltzmann activation parameters and steady-state inactivation were also not different from wtCav3.2 (Fig. 4d, e and Table 1). It is important to note that CAD cells express endogenous voltage-gated calcium channels [19], including T-type channels [13]. Therefore, for our purposes, we analyzed only cells that had current densities higher than $10 \mathrm{pA} / \mathrm{pF}$. Data from our lab (unpublished) have shown that endogenous T-type peak current density in CAD cells has mean values of $\sim 5 \mathrm{pA} / \mathrm{pF}$. The observation that the biophysical effect of the channel mutations appeared to be different in our CAD cell recordings from those obtained with tsA-201 cells could be due to either the different cellular environment or alternatively due to the extracellular solutions. We therefore 
Table 1 Biophysical properties of the wild-type (wtCav3.2) channels and mutants co-expressed (P769L + A1059S) or expressed individually (P769L or A1059S) in tsA-201 cells or CAD cells

\begin{tabular}{|c|c|c|c|c|c|c|}
\hline & $\begin{array}{l}\text { Current density } \\
\text { at }-20 \mathrm{mV}(\mathrm{pA} / \mathrm{pF})\end{array}$ & $G_{\max }(\mathrm{nS})$ & $V_{1 / 2, \text { act }}(\mathrm{mV})$ & $k$ & $V_{1 / 2, \text { inac }}(\mathrm{mV})$ & $k$ \\
\hline \multicolumn{7}{|l|}{ tsA cells } \\
\hline wtCav3.2 & $-53.61 \pm 5.97$ & $0.76 \pm 0.09$ & $-40.02 \pm 0.99$ & $4.42 \pm 0.22$ & $-57.32 \pm 0.91$ & $-4.34 \pm 0.20$ \\
\hline $\mathrm{P} 769 \mathrm{~L}+\mathrm{A} 1059 \mathrm{~S}$ & $-32.50 \pm 5.49$ & $0.50 \pm 0.07 *$ & $-35.43 \pm 1.70 * * *$ & $5.30 \pm 0.42 *$ & $-56.85 \pm 0.92$ & $-5.58 \pm 0.47^{*}$ \\
\hline $\mathrm{P} 769 \mathrm{~L}$ & $-45.74 \pm 5.56$ & $0.71 \pm 0.08$ & $-37.80 \pm 1.05$ & $5.54 \pm 0.22 * * *$ & - & - \\
\hline A1059S & $-38.68 \pm 5.65$ & $0.61 \pm 0.08^{*}$ & $-35.27 \pm 1.57 * *$ & $5.92 \pm 0.55^{* *}$ & - & - \\
\hline \multicolumn{7}{|l|}{ CAD cells } \\
\hline wtCav3.2 & $-32.59 \pm 2.60$ & $0.56 \pm 0.04$ & $-36.45 \pm 0.86$ & $4.97 \pm 0.16$ & $-53.90 \pm 1.07$ & $-4.88 \pm 0.18$ \\
\hline $\mathrm{P} 769 \mathrm{~L}+\mathrm{A} 1059 \mathrm{~S}$ & $-40.07 \pm 3.69(p<0.07)$ & $0.70 \pm 0.061(\mathrm{p}<0.09)$ & $-37.05 \pm 0.79$ & $5.23 \pm 0.19$ & $-56.44 \pm 0.97$ & $-5.35 \pm 0.14(p<0.07)$ \\
\hline
\end{tabular}

${ }^{*} p<0.05 ; * *<0.01 ; * * *<0.005$

conducted another series of recordings in tsA-201 cells, but with $140 \mathrm{mM}$ TEA and no sodium or potassium. Remarkably, the switch in recording solutions eliminated the differences in current densities and half-activation voltages between the wild type and the P769L + A1059S condition ( $n=35-40$, data not shown). Altogether, these data are important in that they reveal recording conditiondependent effects of disease mutations on channel gating.

\section{Discussion}

Given the importance of Cav3.2 channels in epilepsy and pain, we investigated the effects of two heterozygous missense mutations in the $C A C N A 1 H$ gene found in a patient with absence epilepsy and body-wide chronic pain. The two mutations, when expressed in tsA-201 cells (in the absence of high concentrations of TEA), caused a significant decrease in
Fig. 3 P769L and A1059S mutations do not cause any changes in trafficking or expression of channels. Representative western blot showing a surface or $\mathbf{b}$ total expression of wtCav3.2 and mutants expressed in tsA-201 cells. The biotinylation was repeated four times from independent transfections with similar results. Below is the same membrane stripped and re-probed for $\mathrm{Na}^{+} / \mathrm{K}^{+}$ATPase for loading control. Controls are beads (no biotin condition) and mock transfection. c, d Quantification of biotinylations showed by mean \pm SEM of channel expressed as percent of wild-type channels. $n s$ not statistically different from wt. Data analyzed by one-way ANOVA followed by Tukey's test a
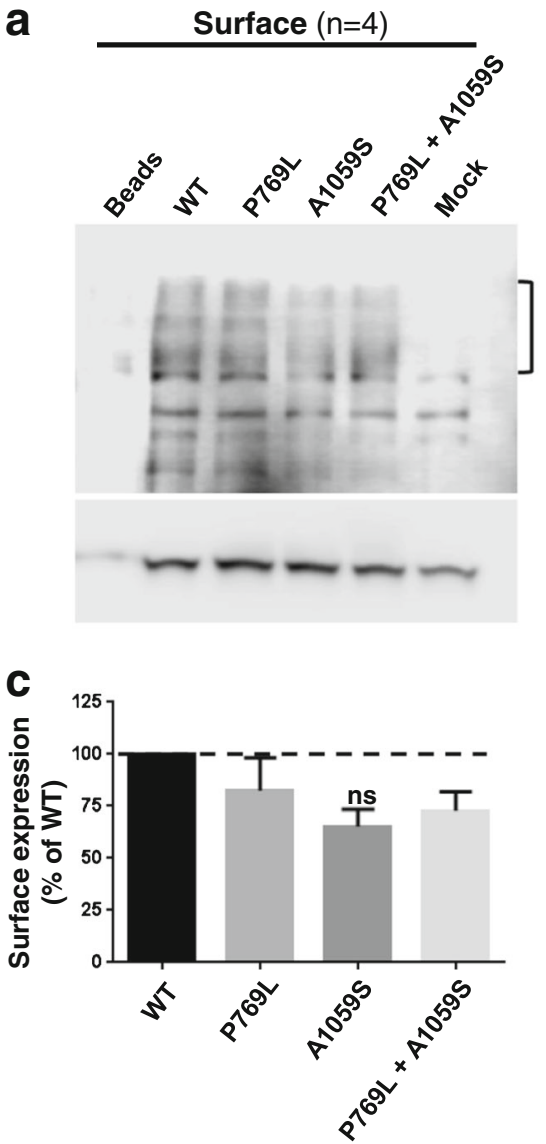

b

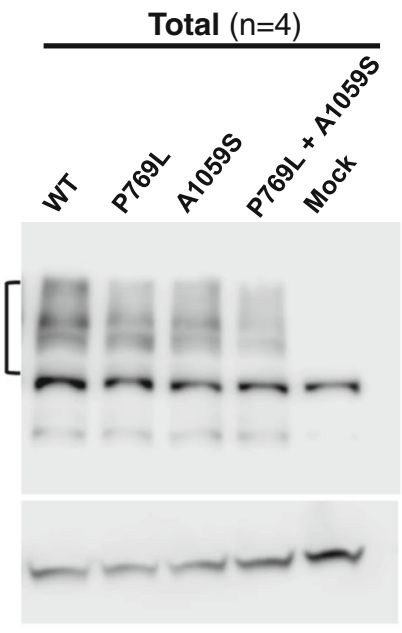

d

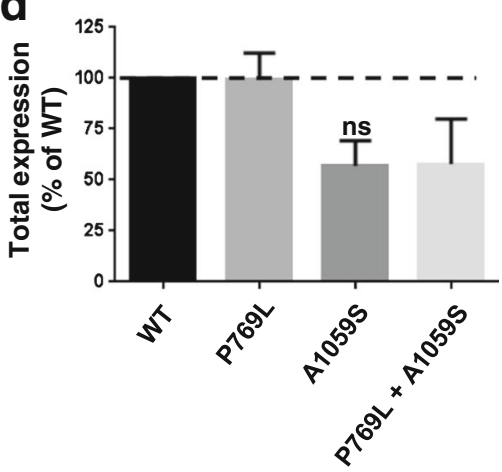


a

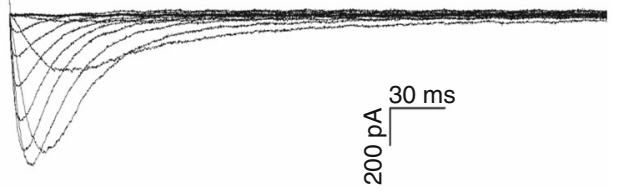

b

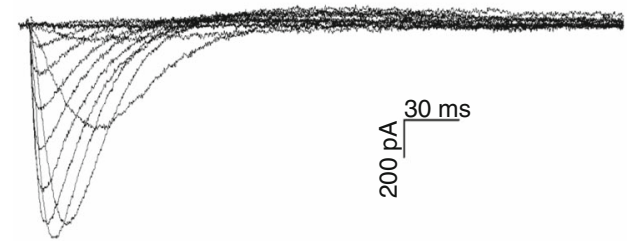

C

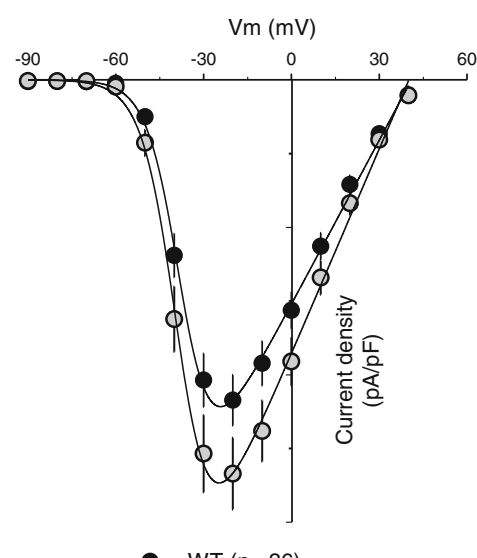

WT $(n=36)$
P769L + A1059S $(n=46)$

Fig. 4 P769L and A1059S channels co-expressed in CAD cells do not present any biophysical difference from wtCav3.2 channels. a Representative current traces recorded from wtCav3.2 channels. b Representative current traces recorded from co-expressed P769L and A1059S channels. Currents were elicited by stepping from a holding potential of $-100 \mathrm{mV}$ to various test potentials. c Average current densities $(\mathrm{pA} / \mathrm{pF})$ as a function of voltage in CAD cells expressing

whole cell current densities and a slight but significant depolarizing shift in the half-activation potential $(\sim 5 \mathrm{mV})$ (Fig. 2a, b), indicating a loss of function of the channels. This result is consistent with a previous study from our lab [6] that had already identified the mutation A1059S as a susceptibility variant in individuals with different generalized epilepsies, and which had revealed that the A1059S mutant, when expressed alone in tsA-201 cells, caused the channels to activate more slowly. In the context of both pain end epilepsy, this loss of function is unexpected as gain of function in Cav3.2 channels is normally associated with these conditions $[9,20$, 21]. However, when both mutations were studied under conditions where the extracellular medium contained high TEA concentrations and no sodium or potassium ions (in both tsA201 and CAD cells), the effects of the mutations on halfactivation voltage and current densities were largely eliminated.

The observation that different recording conditions can yield opposite effects of calcium channel mutations is not without precedent. For example, the familial hemiplegic migraine mutation R192Q in the Cav2.1 calcium channel caused a striking $93 \%$ increase in whole cell current densities of channels expressed in HEK 293 cells, while the same mutation caused a decrease in the current density of human Cav2.1 $\alpha 1$ subunits expressed in cultured mouse Cav2.1 $\alpha 1^{-/-}$neurons. A significant difference in the voltage range of activation $(>20 \mathrm{mV})$ was also found in Cav2.1 channels expressed in HEK 293 cells compared to channels expressed in neurons $[22,23]$. This is not only true for voltage-gated calcium channels, as the ion channel properties of neuronal nicotinic acetylcholine receptors (nAChRs) have also been shown to be dependent on the host cell line [24]. In addition, Cummins et al [25] reported that a TTX-resistant sodium channel Nav1.3 showed a different voltage dependence of steady-state fastinactivation $(\sim 7 \mathrm{mV}$ more depolarized $)$ and a twofold faster rate of repriming when expressed in DRG neurons compared to HEK 293 cells. Neuronal interacting proteins and molecules that regulate these channels might be necessary for proper channel folding, trafficking, and post-translational modifications. In the present case, the data were consistent across the two cell lines used to characterize the channels, but instead were strongly affected by the ionic composition of the extracellular solutions. While it is possible that the observed changes are due to the absence of physiological ions such as sodium 
and potassium, it seems more likely that the culprit is TEA, a quaternary ammonium ion with four ethyl groups that could have the propensity to enter the pore of the channel and weakly block ion permeation. Alternatively, this ion could in principle allosterically alter channel gating. However, why ionic conditions affect biophysical changes induced by a condition where two mutant channels are co-expressed in the same cell is unclear, especially since the mutated residues are not exposed to the extracellular milieu. Nonetheless, the very observation that ionic composition can confound investigations into channelopathies is an important consideration for investigators.

Over 30 different mutations in the $C A C N A 1 H$ gene have been associated with different forms of idiopathic generalized epilepsies [26]. Many of them result in gain of function, such as causing the channels to activate at more hyperpolarized potentials or inactivate slower, which can generate a greater calcium influx and increased neuronal excitability [7, 27]. However, it is not uncommon to find mutations that do not cause any apparent change in channel function or that cause loss of function. For example, several mutations in the Cav3.2 CACNA1H gene found in patients with absence epilepsy do not affect biophysical properties of channels when expressed in heterologous systems $[6,27]$. One explanation could be that rather than causing changes in channel gating per se, they may affect its regulation by second messengers, such as $\mathrm{G}$ proteins, phosphatases, and protein kinases. In fact, one of the mutations studied here, A1059S, is located in the intracellular loops II-III, a hotspot for the action of regulatory pathways [28]. It is important to note that idiopathic epilepsies are complex diseases that have polygenic and multifactorial basis [29]. None of the variants found in the human $C A C N A 1 H$ gene so far is sufficiently pathogenic to cause epilepsies on their own, but instead, act in combination with other variants or even environmental factors to push the level of excitability above the seizure threshold. This may explain why some variants are found in unaffected family members and even in control subjects that do not have epilepsy $[5,6]$.

To our knowledge, epilepsy patients with gain of function mutations in Cav3.2 calcium channels do not typically present with pain. It has been shown that the point mutation in Cav3.2 channel that underlies the phenotype of Genetic Absence Epilepsy Rat of Strasbourg (GAERS) manifests itself functionally only when introduced into a spliced Cav3.2 splice isoform that carries exon 25-an exon that is prominently expressed in the thalamus [30], and it is thus possible that epilepsy mutations may differently affect Cav3.2 channel variants expressed in the afferent pain pathway. Alternatively, it is possible that the contributions of Cav3.2 channel to burst firing are different in afferent neurons compared with the thalamic circuitry.

It is important to note that the patient reported here only started showing symptoms at the age of 9 after a case of mononucleosis. Infectious mononucleosis is a non-genetic syndrome whose major symptoms include fever, pharyngitis, and cervical lymphadenopathy, and it is caused by the Epstein Barr virus in $90 \%$ of the cases [31]. Most symptoms tend to disappear in 2 to 4 weeks, although complications, including neurological disorders, can occur. The incidence of neurologic complications from infectious mononucleosis in the literature range from $0.3 \%$ to $7.3 \%$ and include encephalitis, seizures, optic neuritis, facial palsy, and Guillain-Barré syndrome among others [31-33]. Although most of the neurologic complications from viral infections are acute, it is conceivable that a combination of the mutations in the susceptibility gene $C A C N A 1 H$ and the patient's viral infection combined triggered persistent changes in Cav3.2 channel function, thus giving rise to epilepsy and pain syndrome. Indeed, at least in the afferent pain pathway, Cav3.2 channels can be upregulated in response to inflammation [13] and may potentially undergo changes in splicing, perhaps setting the stage where small changes in channel activity caused by mutations may give rise to pathophysiological consequences.

In summary, we report the first identification of Cav3.2 channel mutations in a patient with persistent pain. The notion that the functional effects of the mutations are strongly dependent on the recording conditions underscores the importance of examining mutant channels in the appropriate intra- and extracellular milieu.

Acknowledgments We thank the patient and her family for their cooperation with our research team. We are grateful to Lina Chen for her technical support. We thank Dr. Francois Bernier for the ExAC database search.

\section{Compliance with ethical standards}

Financial support This work was supported by a grant from the Canadian Institutes of Health Research to GWZ. MAG is supported by a Consejo Nacional de Ciencia y Tecnologia (Mexico) postdoctoral fellowship, and MMW was supported by an Alberta Innovates-Health Solutions summer studentship.

Conflict of interest The authors declare that they have no conflict of interest.

Consent Informed consent was obtained from the mother for the publication of this article.

\section{References}

1. Perez-Reyes E (2003) Molecular physiology of low-voltageactivated t-type calcium channels. Physiol Rev 83:117-161. doi: 10.1152/physrev.00018.2002

2. Cain SM, Snutch TP (2013) T-type calcium channels in burst-firing, network synchrony, and epilepsy. Biochimica et Biophysica Acta (BBA) - Biomembranes 1828:1572-1578. doi:http://dx.doi.org/10. 1016/j.bbamem.2012.07.028 
3. Huguenard J, Prince D (1992) A novel T-type current underlies prolonged $\mathrm{Ca}(2+)$-dependent burst firing in GABAergic neurons of rat thalamic reticular nucleus. The Journal of Neuroscience 12: 3804-3817

4. Eckle VS, Shcheglovitov A, Vitko I, Dey D, Yap CC, Winckler B, Perez-Reyes E (2014) Mechanisms by which a CACNA1H mutation in epilepsy patients increases seizure susceptibility. J Physiol 592:795-809. doi:10.1113/jphysiol.2013.264176

5. Chen Y, Lu J, Pan H, Zhang Y, Wu H, Xu K, Liu X, Jiang Y, Bao X, Yao Z (2003) Association between genetic variation of CACNA1H and childhood absence epilepsy. Annals of neurology 54:239-243

6. Heron SE, Khosravani H, Varela D, Bladen C, Williams TC, Newman MR, Scheffer IE, Berkovic SF, Mulley JC, Zamponi GW (2007) Extended spectrum of idiopathic generalized epilepsies associated with CACNA1H functional variants. Ann Neurol 62: 560-568. doi:10.1002/ana.21169

7. Khosravani H, Altier C, Simms B, Hamming KS, Snutch TP, Mezeyova J, McRory JE, Zamponi GW (2004) Gating effects of mutations in the Cav3.2 T-type calcium channel associated with childhood absence epilepsy. J Biol Chem 279:9681-9684. doi:10. 1074/jbc.C400006200

8. Khosravani H, Bladen C, Parker DB, Snutch TP, McRory JE, Zamponi GW (2005) Effects of Cav3.2 channel mutations linked to idiopathic generalized epilepsy. Ann Neurol 57:745-749. doi:10. 1002/ana.20458

9. Bourinet E, Altier C, Hildebrand ME, Trang T, Salter MW, Zamponi GW (2014) Calcium-permeable ion channels in pain signaling. Physiol Rev 94:81-140. doi:10.1152/physrev.00023.2013

10. Zamponi GW, Striessnig J, Koschak A, Dolphin AC (2015) The physiology, pathology, and pharmacology of voltage-gated calcium channels and their future therapeutic potential. Pharmacol Rev 67: 821-870. doi:10.1124/pr.114.009654

11. Bourinet E, Alloui A, Monteil A, Barrere C, Couette B, Poirot O, Pages A, McRory J, Snutch TP, Eschalier A, Nargeot J (2005) Silencing of the Cav3.2 T-type calcium channel gene in sensory neurons demonstrates its major role in nociception. EMBO J 24: 315-324. doi:10.1038/sj.emboj.7600515

12. Francois A, Kerckhove N, Meleine M, Alloui A, Barrere C, Gelot A, Uebele VN, Renger JJ, Eschalier A, Ardid D, Bourinet E (2013) State-dependent properties of a new T-type calcium channel blocker enhance $\mathrm{Ca}(\mathrm{V}) 3.2$ selectivity and support analgesic effects. Pain 154:283-293. doi:10.1016/j.pain.2012.10.023

13. Garcia-Caballero A, Gadotti VM, Stemkowski P, Weiss N, Souza IA, Hodgkinson V, Bladen C, Chen L, Hamid J, Pizzoccaro A, Deage M, Francois A, Bourinet E, Zamponi GW (2014) The deubiquitinating enzyme USP5 modulates neuropathic and inflammatory pain by enhancing Cav3.2 channel activity. Neuron 83: 1144-1158. doi:10.1016/j.neuron.2014.07.036

14. Berger ND, Gadotti VM, Petrov RR, Chapman K, Diaz P, Zamponi GW (2014) NMP-7 inhibits chronic inflammatory and neuropathic pain via block of Cav3.2 T-type calcium channels and activation of CB2 receptors. Mol Pain 10:77. doi:10.1186/1744-8069-10-77

15. Cao XH, Byun HS, Chen SR, Pan HL (2011) Diabetic neuropathy enhances voltage-activated $\mathrm{Ca} 2+$ channel activity and its control by M4 muscarinic receptors in primary sensory neurons. J Neurochem 119:594-603. doi:10.1111/j.1471-4159.2011.07456.x

16. Wen XJ, Li ZJ, Chen ZX, Fang ZY, Yang CX, Li H, Zeng YM (2006) Intrathecal administration of Cav3.2 and Cav3.3 antisense oligonucleotide reverses tactile allodynia and thermal hyperalgesia in rats following chronic compression of dorsal root of ganglion. Acta Pharmacol Sin 27:1547-1552. doi:10.1111/j.1745-7254.2006. 00461.x

17. Weiss N, Black SA, Bladen C, Chen L, Zamponi GW (2013) Surface expression and function of Cav3.2 T-type calcium channels are controlled by asparagine-linked glycosylation. Pflugers Arch 465:1159-1170. doi:10.1007/s00424-013-1259-3

18. Qi Y, Wang JK, McMillian M, Chikaraishi DM (1997) Characterization of a CNS cell line, CAD, in which morphological differentiation is initiated by serum deprivation. The Journal of Neuroscience 17:1217-1225

19. Wang H, Oxford GS (2000) Voltage-dependent ion channels in CAD cells: a catecholaminergic neuronal line that exhibits inducible differentiation. Journal of Neurophysiology 84:2888-2895

20. Khosravani H, Zamponi GW (2006) Voltage-gated calcium channels and idiopathic generalized epilepsies. Physiol Rev 86:941966. doi:10.1152/physrev.00002.2006

21. Waxman SG, Zamponi GW (2014) Regulating excitability of peripheral afferents: emerging ion channel targets. Nat Neurosci 17: 153-163. doi: $10.1038 / \mathrm{nn} .3602$

22. Hans M, Luvisetto S, Williams ME, Spagnolo M, Urrutia A, Tottene A, Brust PF, Johnson EC, Harpold MM, Stauderman KA (1999) Functional consequences of mutations in the human $\alpha 1 \mathrm{~A}$ calcium channel subunit linked to familial hemiplegic migraine. The Journal of Neuroscience 19:1610-1619

23. Tottene A, Fellin T, Pagnutti S, Luvisetto S, Striessnig J, Fletcher C, Pietrobon D (2002) Familial hemiplegic migraine mutations increase $\mathrm{Ca}(2+)$ influx through single human $\mathrm{CaV} 2.1$ channels and decrease maximal CaV2.1 current density in neurons. Proc Natl Acad Sci U S A 99:13284-13289. doi:10.1073/pnas.192242399

24. Lewis TM, Harkness PC, Sivilotti LG, Colquhoun D, Millar NS (1997) The ion channel properties of a rat recombinant neuronal nicotinic receptor are dependent on the host cell type. The Journal of Physiology 505:299-306. doi:10.1111/j.14697793.1997.299bb.x

25. Cummins TR, Aglieco F, Renganathan M, Herzog RI, Dib-Hajj SD, Waxman SG (2001) Nav1. 3 sodium channels: rapid repriming and slow closed-state inactivation display quantitative differences after expression in a mammalian cell line and in spinal sensory neurons. The Journal of Neuroscience 21:5952-5961

26. Zamponi GW (2015) Targeting voltage-gated calcium channels in neurological and psychiatric diseases. Nat Rev Drug Discov. doi: 10.1038/nrd.2015.5

27. Peloquin JB, Khosravani H, Barr W, Bladen C, Evans R, Mezeyova J, Parker D, Snutch TP, McRory JE, Zamponi GW (2006) Functional analysis of Ca3.2 T-type calcium channel mutations linked to childhood absence epilepsy. Epilepsia 47:655-658. doi: 10.1111/j.1528-1167.2006.00482.x

28. Iftinca MC, Zamponi GW (2009) Regulation of neuronal T-type calcium channels. Trends Pharmacol Sci 30:32-40. doi:10.1016/j. tips.2008.10.004

29. Dibbens LM, Heron SE, Mulley JC (2007) A polygenic heterogeneity model for common epilepsies with complex genetics. Genes Brain Behav 6:593-597. doi:10.1111/j.1601-183X.2007.00333.x

30. Powell KL, Cain SM, Ng C, Sirdesai S, David LS, Kyi M, Garcia E, Tyson JR, Reid CA, Bahlo M, Foote SJ, Snutch TP, O'Brien TJ (2009) A Cav3.2 T-type calcium channel point mutation has splice-variant-specific effects on function and segregates with seizure expression in a polygenic rat model of absence epilepsy. $\mathrm{J}$ Neurosci 29:371-380. doi:10.1523/JNEUROSCI.5295-08.2009

31. Lennon P, Crotty M, Fenton JE (2015) Infectious mononucleosis. BMJ 350:h1825. doi:10.1136/bmj.h1825

32. Connelly KP, DeWitt LD (1994) Neurologic complications of infectious mononucleosis. Pediatric Neurology 10:181-184. doi:10. 1016/0887-8994(94)90021-3

33. Silverstein A, Steinberg G, Nathanson M (1972) Nervous system involvement in infectious mononucleosis: the heralding and/or major manifestation. Archives of Neurology 26:353-358 